\title{
THE MYRMECOPHILOUS BEETLE GENUS ECHINOCOLEUS \\ IN THE SOUTHWESTERN UNITED STATES (LEIODIDAE; CATOPINAE)*
}

\author{
By Stewart B. Peck \\ Department of Biology, Carleton University, \\ Ottawa, Ontario K1S 5B6, Canada
}

The genus Echinocoleus and the species E. setiger were described by Horn (1885) from two specimens from an unspecified locality in Arizona. Jeannel (1936) placed the genus in the subfamily Nemadinae and the tribe Nemadini based on a statement by Hatch (1933, p. 191) who had not seen specimens. Jeannel also placed the species Dissochaetus arizonensis Hatch in the genus Echinocoleus, which he would not have done had he seen specimens of either. Peck (1973) after seeing the types of both genera, placed Echinocoleus in the tribe Ptomaphagini and subtribe Ptomaphagina of the subfamily Catopinae, and reviewed what little was known of the genus.

Recently, Dr. D. E. Foster (Entomology Section, Agricultural Sciences, Texas Tech University, Lubbock, Texas) collected a series of Echinocoleus from nests of Pogonomyrmex harvester ants in west Texas. These specimens prompted me to study this interesting myrmecophilous beetle genus as part of a projected series reviewing the systematics and evolutionary biology of the Catopinae of North America.

The methods, terminology, and format of this paper follow those of my previous studies (Peck 1973, 1976). Dried and pinned specimens were relaxed for 24 hours by soaking in a small dish of distilled water with two drops of liquid detergent, and were then dissected under $70 \%$ alcohol. Drawings were made of structures on temporary slide mounts or embedded in glycerine jelly.

\section{Genus Echinocoleus}

Echinocoleus Horn, 1885, p. 136. Type species E. setiger by monotypy, type seen, in $\mathrm{MCZ}$.

*Manuscript received by the editor May 20, 1976 
Diagnosis. Shape widely oval or "limuloid", elytra with long semi-erect golden hairs, mesosternal keel absent. These characters plus the habit of living with Pogonomyrmex and Novomessor ants in the southwestern U. S. distinguish this genus from other Ptomaphagini (keys to the genera are in Peck, 1973, 1976).

Description of genus. Length 1.9-2.8 mm. Width 1.4-1.8 mm. Color pale yellowish to reddish brown. Form widely oval, 1.4-1.9 times as long as wide; flattened (figs. 1-3). Head compressed, closely retractile onto thorax; surface smooth, with short, or short and long hairs; eyes large. Maxillary palpi with last segment conical, shorter than preceding segment. Antennae short, not reaching beyond middle of pronotum when laid back; all segments except first three transverse; club somewhat flattened, composed of last eight segments, which uniformly increase in width, so that XI is widest; segment VIII shorter than but as wide as VII and IX. Pronotum widest slightly before base; 1.7 to 2 times as wide as long; sides regularly arcuate; hind angles drawn out but rounded; hind margin straight in middle; striae present or absent on disc; covered with recumbent short or recumbent short and semi-erect long hairs. Elytra widest at base, 1.0-1.2 times as wide as long; external apical angles rounded, hind margins truncate; sutural angles sharp in male and female; striae somewhat oblique to suture, more transverse away from suture; dense vestiture of short, recumbent hairs and about 10 longitudinal rows of long, semi-erect golden hairs (fig. 4). Flight wings fully formed and apparently functional. Mesosternum with evident midline but lacking median carina. Mesocoxae slightly separated; metacoxae contiguous. Mesepimeron of Ptomaphagina type, trapezoidal. Legs short, flattened; capable of being closely adpressed to body; all tibiae with comb of short equal spines on summit; protarsi expanded in males, distinctly or indistinctly narrower in females; mesotarsi not expandęd in either sex; all tarsi five segmented. Aedeagus in side view blunt at base, gradually tapering to narrow tip; style of internal sac long, thin, twisted, with detached basal bulb; in dorsal view narrowing gradually toward tip, tip a blunt point; setae present or absent on aedeagal tip; parameres long, thin, lying close to aedeagus, with three apical setae. Genital plates twice as long as broad, with abundant long hairs at orifice; median spiculum gastrale elongate, projecting one half length beyond anterior end of genital plates. Spermatheca with narrow posterior, and with crest on larger swollen twisted anterior end. 
Distribution and biology. The genus contains three species, two described below as new. The species are known to occur only in the Sonoran and Chihuahuan desert and adjacent arid regions of the southwestern United States in Arizona, New Mexico, and Texas (and probably in adjacent Mexico). All detailed collection data suggest that the species live in nests of Pogonomyrmex "harvester" and Novomessor ants. The limuloid or turtle-like body form indicates that the beetle has some need for a defensive design against the host ants. We may guess that the beetle is a synoekete, being generally ignored or indifferently tolerated by the ants. We may also guess that the beetles scavenge waste materials in the nests, because catopine beetles are generally scavengers. Dr. Foster has observed the beetle larvae most often in the presence of ant brood, and notes that both larvae and adults seem to be free living, with no phoretic association with the ants.

Observations and label data suggest that adult beetles occur more frequently and are easiest to collect in the cooler months when the ants are less active. My experiences with many painful stings received in opening Pogonomyrmex nests in the summer in Texas and Mexico convinced me that this is the wrong time of year. Additional records of species distribution and observations of behavioral association with the ants are needed.

Larvae of two species of beetles have been recovered from harvester ant nests. They are modified from the usual elongate shape of catopine larvae into very broad, flat forms with abundant, large, and thick setae. These larvae have been deposited in the MCZ.

The record of Echinocoleus from a Pogonomyrmex nest at Selma, Alabama (Peck, 1973) was in error. The specimen is a Ptomaphagus of a species unknown to me. This alone reinforces the need for additional study of the catopine beetles in the nests of harvester ants.

\section{Echinocoleus setiger Horn}

Echinocoleus setiger Horn, 1885: 136. Lectotype here designated as male in MCZ (Horn colln.) bearing red label printed "Lectotype" and with the handwritten number "2995," and a small white label "Ari". Type series consists of one other specimen, a female, bearing a blue-green label "Paratype, 2995," MCZ (Horn colln.). Both seen. Type locality: "Arizona."

Diagnosis. The species is distinguished by its larger size, more transverse pronotum with fine distinct striae and semi-erect coarse hairs, fine elytral striae, and spermathecal shape. It occurs in grass- 
land or woodland habitats, and is associated with Novomessor ants.

Description. Body color dark brown. Size $2.5-2.7 \mathrm{~mm}$ long; 1.7-1.9 mm wide; 1.4 times as long as wide, widest across pronotum. Pronotum 1.7-1.8 mm wide; 1.9-2.1 times as wide as long. Elytral width across scutellum tip 1.1-1.2 times greater than elytral length from scutellum tip. Head and pronotum as well as elytra with stiff semi-erect golden hairs. Pronotal striae distinct. Elytral striae finely spaced, about 5 per $0.1 \mathrm{~mm}$. Aedeagus (figs. 5 and 6 ), with narrower tip in dorsal view, without terminal setae or down-curved tip in side view. Spermatheca with elongated crest on anterior globular bulb (figs. 7-9).

Variation. No variation is noted.

Additional material examined. Arizona. Cochise County. Huachuca Mountains, Miller Canyon, W. M. Mann coll., 1 male pinned with Novomessor albisetosus (Mayr) (my determination), USNM. Huachuca Mountains, Garden Canyon, 13 Nov. 1910, W. M. Wheeler, W. M. Mann colln., 1 male pinned with Novomessor albisetosus (my determination), USNM. Graham County. Galiuro Mountains, 22.5 (= 22 May), Hubbard and Schwarz coll., 1 female, USNM. Pinal County. Oracle, 5000 feet elev., 11 March 1919, W. M. Wheeler, 1 female pinned with two Novomessor albisetosus (F. G. Werner determination), MCZ.

Biology. The collection data show that the beetle occurs with Novomessor albisetosus (Mayr) ants. Brown (1974) has indicated that the proper generic assignment of the ant may be Aphaenogaster. These ants range across much of the arid southwestern US and adjacent Mexico (Creighton, 1950, 1955; Wheeler and Creighton, 1934), and so might the beetle. Since the ants occasionally nest under stones (Creighton, 1950), the beetles might be found there without the need of digging into the ants' nests. The ants occur most frequently on the lower slopes of desert mountain ranges (Creighton, 1950), and the beetle records suggest an affinity for a higher elevation Sonoran desert woodland or grassland rather than a lower elevation desert shrub habitat. Although some of the above specimens were taken by W. M. Wheeler with Novomessor, nothing is mentioned about the presence of these beetles in his revision of this ant genus (Wheeler and Creighton, 1934).

Echinocoleus sonorensis sp. $n$.

Holotype male in MCZ (no. 32309). Type locality: Arizona, Pima County, Tucson. Type data: 1.iv.1970, P. Ritchie et al., in 
nest of Pogonomyrmex rugosus Emory, a harvester ant (F. G. Werner determination). Paratypes: One male and one female with same data (SBP colln.).

Diagnosis. The species is distinguished by its larger size, more transverse pronotum without distinct striae or semi-erect coarse hairs, and more widely spaced elytral striae. The species is found in lower elevation Sonoran desert shrubland habitats, in association with Pogonomyrmex ants.

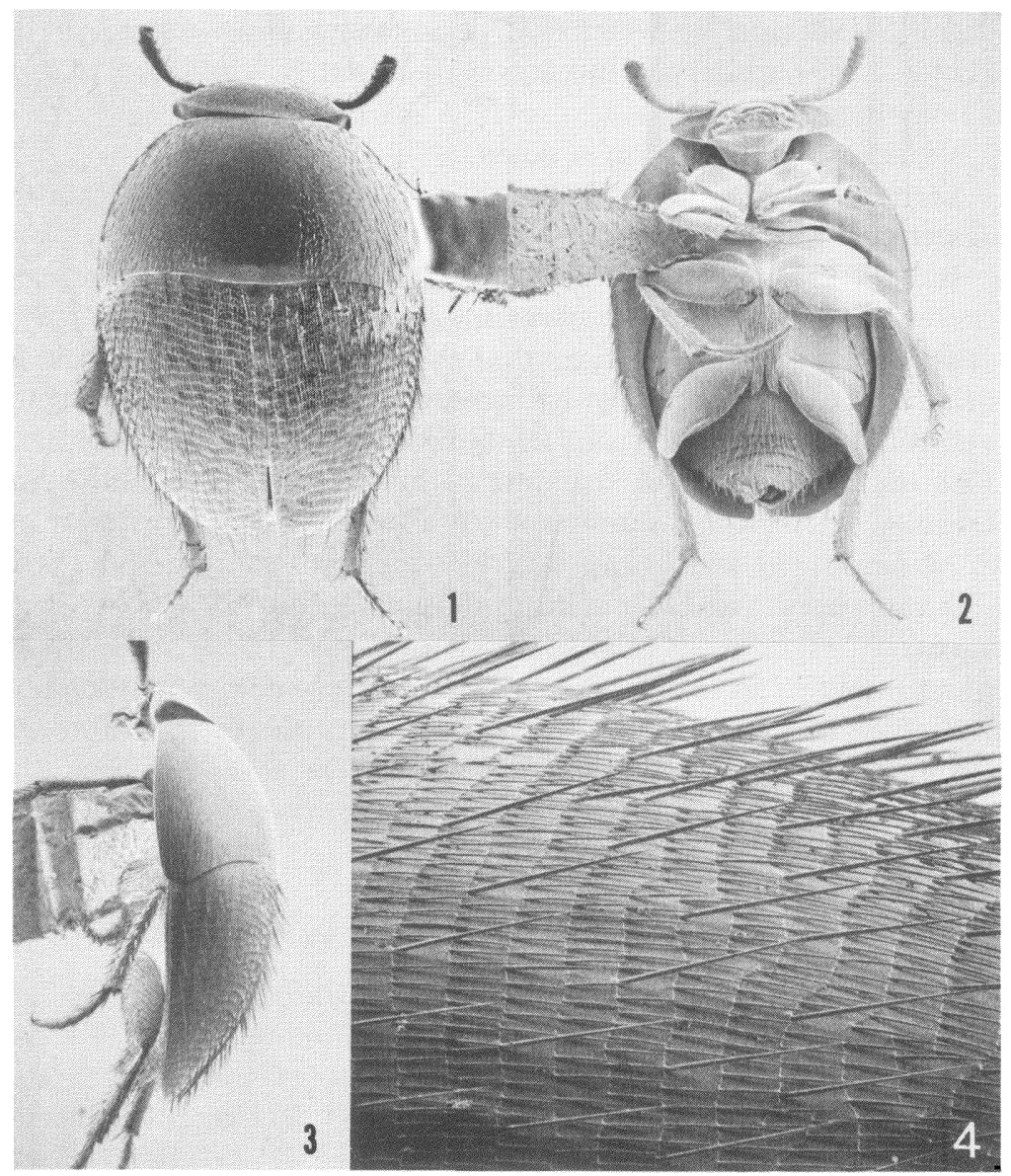

Figures 1-4. SEM photomicrographs of Echinocoleus sonorensis. 1-3. Dorsal, ventral, and lateral views respectively. 4. Lateral view of elytra showing long, semierect hairs. 
Description. Body color pale; golden brown. Size $2.5-2.8 \mathrm{~mm}$ long; 1.6-1.8 mm wide; $1.5-1.6$ times as long as wide; widest across pronotum. Pronotum 1.8-1.9 mm wide; 1.8-1.9 times as wide as long. Elytral width across scutellum tip 1.2-1.3 times greaer than elytral length from scutellum tip. Head and pronotum without, but elytra with, stiff and semi-erect golden hairs; fine recumbent setae on all dorsal surfaces except polished pronotal disc. Pronotal microsculpture and striae absent. Elytral striae coarsely spaced, about 2 per $0.1 \mathrm{~mm}$. Genital plate and spiculum gastrale as in figure 10. Aedeagus tip wider (fig. 11), without down-curved tip in side view. Spermatheca unknown; damaged in dissection of the unique female.

Variation. No variation is noted.

Etymology. The name refers to the arid grassland and shrub desert region of Arizona and adjacent parts of Mexico.

Biology. The beetle is known to occur only with Pogonomyrmex rugosus Emory, one of the harvester ants. Dr. Floyd Werner (personal communication) reports that the specimens were taken in a nest of this ant in the upper half meter. The nest was excavated to a depth of about 3 meters, and contained more than 22,000 workers. This nest was similar in structure to that excavated in Maricopa County, Arizona, and reported by Wildermuth (1931) as a nest of $P$. barbatus, but which was most likely a nest of $P$. rugosus. The host ant ranges over much of the arid southwestern US and adjacent Mexico (Creighton, 1950; Cole, 1968) and so might the beetle. One highly modified larva was taken in April with the adults in the upper part of the nest (deposited in MCZ). The ants usually nest in stony soil in open deserts (Creighton, 1950) and the general vegetation in the vicinity of Tucson is an open lower elevation Sonoran shrub and cactus desert.

\section{Echinocoleus chihuahuensis sp. $\mathrm{n}$.}

Holotype female and allotype male in California Academy of Sciences. Type locality: Texas, Culberson County, $5.5 \mathrm{mi}$ N Pine Springs (west Dog Canyon, 5300-5400 ft. elev., in Guadelupe Mountains National Park). Type data: 2.x.1975, D. E. Foster collector, in nests of Pogonomyrmex maricopa Wheeler (Foster determination). Paratypes: ten with same data, and three with same data but 9.vi.1974 (deposited in MCZ, Texas Tech, and SBP collections). 
New Mexico. San Miguel County. Las Vegas, A. Fenyes, three females pinned with Pogonomyrmex maricopa (my determination), MCZ, CAS.

Diagnosis. The species is distinguished by its smaller size, less transverse pronotum lacking striae but possessing stiff semi-erect hairs, medium fine elytral striae, downward curved aedeagus tip in lateral view, and shape of the spermetheca. The species is found in upper elevation Chihuahuan desert grassland-woodland habitat, in association with Pogonomyrmex ants.

Description. Body color brown. Size 1.9-2.3 mm; 1.4-1.5 mm wide; 1.3-1.5 times as long as wide, widest across pronotum. Pronotum 1.7-1.8 times as wide as long. Elytral width across scutellum tip 1.0-1.1 times elytral length from scutellum tip. Stiff semi-erect hairs on head, prothorax, and elytra. Pronotal striae absent but very fine and light microsculpture present. Elytral striae distinct, about three per $0.1 \mathrm{~mm}$. Aedeagus tip narrower (fig. 12), with terminal setae, and downcurved tip in side view. Spermatheca with shorter crest on flattened anterior bulb (figs. 13-15).

Variation. No variation is noted.

Etymology. The name refers to the arid grassland and shrub desert region of Texas and New Mexico and adjacent parts of Mexico.

Field notes. The type habitat (in Culberson Co.) is a shrub and cactus desert. The dominant plant is perennial broomweed, Xanthocephalum sarothrae (Pursh) Shinners. The beetles were collected here by digging laterally into the ant nests from the side of a small ravine, and aspirating the ants and beetles as they appeared.

Biology. The beetle is probably widespread in nests of the harvester ant, Pogonomyrmex maricopa Wheeler, throughout much of the Chihuahuan region. The ant itself has a wider range in the arid southwest (Creighton, 1950; Cole, 1968). Dr. Foster has provided the following additional observations. Beetle larvae have been found in ant nests only at depths of over two feet, and larvae are usually in the presence of ant brood. Both larvae and adults appear to be free living, and no contact with the ants or trophallaxis or phoresy has been observed. There appears to be a single generation per year, with eggs being deposited early in the spring, mature larvae appearing by early September, and the winter passed as an adult. Additional careful study of the habits of the beetle is needed. 

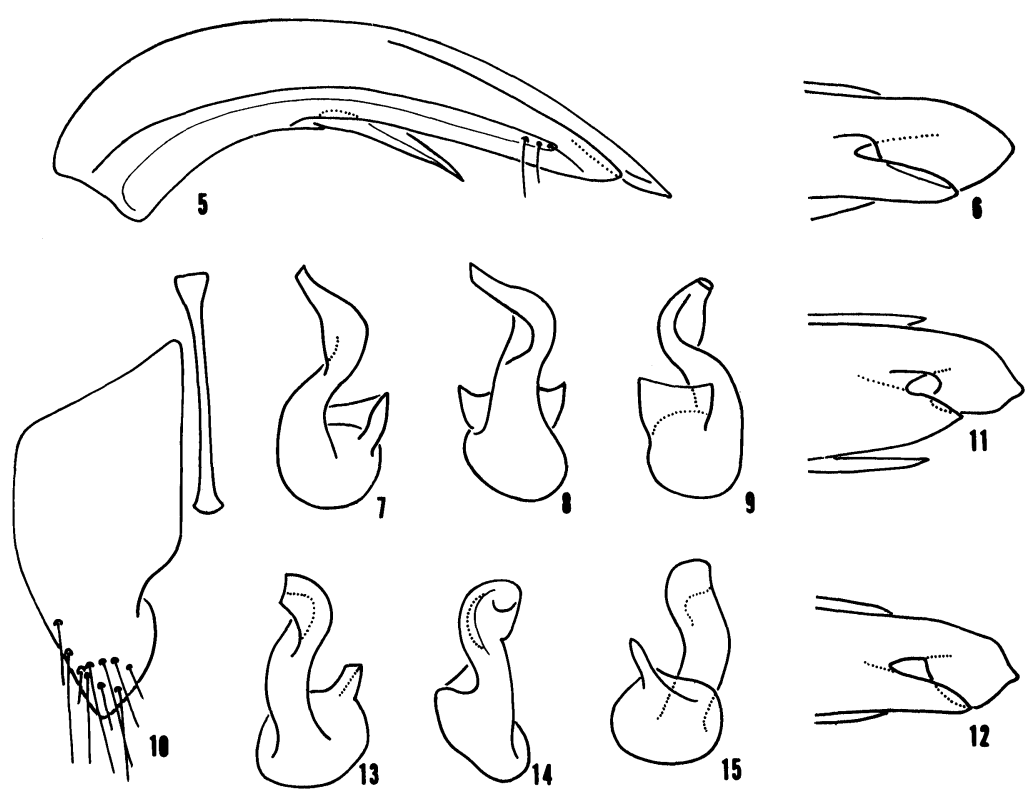

Figures 5-15. Structures of Echinocoleus. 5. E. setiger, holotype, lateral view of aedeagus. 6. E. setiger, holotype, dorsal view of aedeagus tip. 7, 8, and 9. E. setiger, three views of spermatheca, from Galiuro mountains, Arizona. 10. $E$. sonorensis, right genital plate and spiculum gastrale, holotype. 11. E. sonorensis, holotype, dorsal view of aedeagus tip. 12. E. chihuahuensis, allotype, dorsal view of aedeagus tip. 13,14, and 15. E. chihuahuensis, holotype, three views of spermatheca.

\section{Phylogeny, Speciation, and Zoogeography}

The genus is a specialized offshoot of a New World Ptomaphagus (Adelops) ancestor which has taken up a life of myrmecophily, with all the behavioral and morphological specialization that this implies and requires (Wilson, 1971). The spermatheca suggests that the genus is derived from the consobrinus species group of Ptomaphagus. One species within this group, $P$. texanus Melander, occurs today in Pogonomyrmex nests at Austin, Texas (Peck, 1973). Another myrmecophilous catopine genus, Synaulus, is a North African derivative of an Old World Ptomaphagus (Ptomaphagus) ancestor.

A phylogenetic interpretation of characters in Echinocoleus as a genus, with the Ptomaphagus consobrinus species group as the comparative sister group, leads to an interpretation of the following 
generic characters as apotypic; the limuloid shape, the lack of a mesosternal carina, and the long, semi-erect hairs. These are obvious adaptations to myrmecophily. Other characters vary between the species and are judged to proceed from a plesiotypic to an apotypic state as follows: long dorsal hairs on all dorsal surfaces to on elytra only; pronotal striae present to absent; elytral striae from closely spaced to widely spaced; aedeagus tip from narrow to broad in dorsal view; color dark brown to light brown; and spermatheca crest from narrow to elongate. Comparison of these states with data given in the species descriptions leads to the conclusion that $E$. sonorensis possesses the greatest number of apotypic characters, $E$. chihuahensis possesses a mixture of pleisotypic and two intermediately apotypic characters, and $E$. setiger possesses all but one character in a pleisotypic condition. A parsimonious splitting sequence is determined by that involving the fewest convergencies (Ball, 1976). Thus, sonorensis is the sister group of the stock that gave rise to the other two species. In this scheme the reduction of pronotal striae, coarsening of elytra striae, and pronotal broadening have each occurred twice.

Using this phylogenetic interpretation, applying the zoogeographic and evolutionary clues of Darlington (summarized by Erwin, 1970: 184), and considering known and surmised paleobotanic and paleoclimatic conditions, I propose the following scenario of sequential events.

1. The aridity of the southwest increased in the second half of the Tertiary. Grasslands and thorn scrub desert areas developed in the Miocene, especially in the rain shadows of the developing mountain ranges (Axelrod, 1958; Cohn, 1965). Since I know of no speculation of the subject, I suggest that Pogonomyrmex and Novomessor, both comparatively primitive myrmecine ant genera came to occupy these developing arid habitats at this time. The ants were already present because Pogonomyrmex, Aphaenogaster, and Messor (interpreted by Creighton (Wheeler and Creighton, 1934: 360) (as Pogonomyrmex) occur in the Upper Oligocene Florissant shale of Colorado (Carpenter, 1930).

2. The increasing aridity of the late Pliocene and especially of the Pleistocene led to development of part of the already existing southwestern Madro-Tertiary Geoflora into the diverse and distinct Sonoran desert vegetation (Axelrod, 1958).

3. A species of Ptomaphagus in the consobrinus group invaded 
Pogonomyrmex ant nests in the developing Pliocene Sonoran desert, became isolated and, under selective pressures applied by ants, differentiated into Echinocoleus.

4. This early Echinocoleus extended its range eastward into higher elevation grassland and woodland habitats and eventually into the Rio Grande River drainage and the developing Chihuahuan desert. The lack of similarity in the vegetation of the two deserts show they have been isolated by intervening regions of forest, woodland, or grassland since the start of Tertiary regional aridity.

5. The ancestral Echinocoleus separated into a lower elevation sonorensis ancestor and a higher elevation setiger-chihuahuensis ancestor, and the first proceeded to differentiate more rapidly than the second, probably through ant-applied selective pressures.

6 . The separation of the woodland-grassland range of setigerchihuahuensis into an eastern (Texas-New Mexico) chihuahuensis ancestor and a western (Arizona) setiger ancestor occurred during a Pleistocene glacial when extensive conifer forests occupied the north-south trending mountainous region of eastern Arizona and western New Mexico (Martin and Mehringer, 1965). The forest extended south to the Sierre Madre Occidental at the western edge of the Mexican Plateau. In at least the last glacial this forested barrier was unsuited for Pogonomyrmex and thus for Echinocoleus, and it was probably similarly unsuited in earlier glacials. During these glacials, the Sonoran desert was diminished in size and pushed closer to the Gulf of California, and the Chihuahuan desert was reduced to lower elevation regions of the Rio Grande drainage (Wells, 1966). This greater separation of arid Sonoran and Chihuahuan regions is known to have caused range separation, divergence, and formation of species pairs in many groups of arid-land insects (Cohn, 1965; Howden, 1969).

7. The western setiger ancestor shifted into an occupation of Novomessor ant nests.

8. The three isolated stocks of Echinocoleus then differentiated into the three present species.

9. Since the last glacial maximum, some of the species of Pogonomyrmex have expanded from either or both of their contracted Sonoran or Chihuahuan refugia to their presently continuous and overlapping ranges, covering most of the southwestern US. Echinocoleus came to occupy their present non-overlapping ranges following the ants' readjustments to the present, post-glacial climaticvegetational conditions. 
I hope that this hypothetical series can be further tested with additional information on yet unknown species, and on additional distributional and host data for the known species.

\section{ACKNOWLEDGEMENTS}

J. F. Lawrence, H. F. Howden, and W. L. Brown, Jr., reviewed all or parts of the manuscript. F. Werner (University of Arizona, Tucson), A. Newton (MCZ), D. E. Foster (Texas Tech), D. Kavanaugh (CAS), and J. M. Kingsolver (USNM) loaned or contributed specimens from their collections or collections under their care. My field work in the southwestern US was supported by a Canadian National Research Council operating grant. Drs. Brown, Foster, and Werner contributed information from their studies of the host ants.

\section{Literature Cited}

Axelrod, D.

1958. Evolution of the Madro-Tertiary geoflora. Bot. Rev. 24: 433-509.

BALL, G. E.

1976. Aztecarpalus Ball: New species from Oaxaca, Mexico, re-classification, and a reconstructed phylogeny of the hebescens group (Coleoptera: Carabidae: Harpalini). Coleopterists Bull., 30: 61-72.

Brown, W. L., JR.

1974. Novomessor manni a synonym of Aphaenogaster ensifera (Hymenoptera: Formicidae). Ent. News, 85: 45-47.

CARPENTER, F. M.

1930. The fossil ants of North America. Bull. Mus. Comp. Zool., Harvard Univ., 70, no. 1, 69 pp.

Coнn, T. J.

1965. The arid-land Katydids of the North American genus Neobarrettia (Orthoptera: Tettigoniidae): their systematics and a reconstruction of COLE, A. C., JR. their history. Univ. Michigan, Mus. Zool., Misc. Publ. 126, 179 pp.

1968. Pogonomyrmex harvester ants: a study of the genus in North America. Univ. Tenn. Press, Knoxville. 222 pp.

Creighton, W. S.

1950. The ants of North America. Bull. Mus. Comp. Zool., Harvard Univ., 104: 585 pp., 57 plates.

1955. Studies on the distribution of the genus Novomessor (Hymenoptera: Formicidae). Psyche, 62: 89-97.

ERWIN, T. L.

1970. A reclassification of bombardier beetles and a taxonomic revision of the North and Middle American species (Carabidae; Brachinida). Quaest. Ent. 6: 4-215. 
НатсH, M. W.

1933. Studies on the Leptodiridae (Catopidae) with descriptions of new species. J. New York Entomol. Soc., 41: 187-239.

HORN, G. H.

1885. Contributions to the Coleopterology of the United States, no. 4. Trans. Amer. Ent. Soc., 12: 128-162.

HowdEN, H. F.

1969. Effects of the Pleistocene on North American insects. Ann. Rev. Ent., 14: $39-56$.

JEANNEL, R.

1936. Monographie des Catopidae. Mem. Mus. Natl. Hist. Natur., Paris, n.s., $1,433 \mathrm{pp}$.

Martin, P. S., and J. P. Mehringer, JR.

1965. Pleistocene pollen analysis and biogeography of the Southwest. pp. 433451. In H. E. Wright, Jr., and D. G. Frey, Eds., The Quaternary of the United States. Princeton Univ. Press, Princeton. 922 pp.

PeCK, S. B.

1973. A systematic review and the evolutionary biology of the Ptomaphagus Adelops) beetles of North America (Coleoptera, Leiodidae; Catopinae), with emphasis on cave-inhabiting species. Bull. Mus. Comp. Zool., Harvard Univ., 145(2): 29-162.

PeCK, S. B.

1976. The subterranean and epigean Catopinae of Mexico (Coleoptera; Leiodidae). Occ. Papers Texas Tech Univ. Museum, in press.

Wells, P. B.

1966. Late Pleistocene vegetation and degree of pluvial climatic change in the Chihuahuan Desert. Science 153: 970-976.

Wheeler, W. M., and W. S. Creighton

1934. A study of the ant genera Novomessor and Veromessor. Proc. Amer. Acad. Arts Sci. Boston, 69(9): 341-387, 2 pls.

WiLDERMUTH, V. L.

1931. The red harvester ant and how to subdue it. U.S. Dept. Agric. Farmers' Bull. 1668, $21 \mathrm{pp}$.

WILSON, E. O.

1971. The Insect Societies. Belknap Press, Harvard University, Cambridge, Mass., $548 \mathrm{pp}$. 

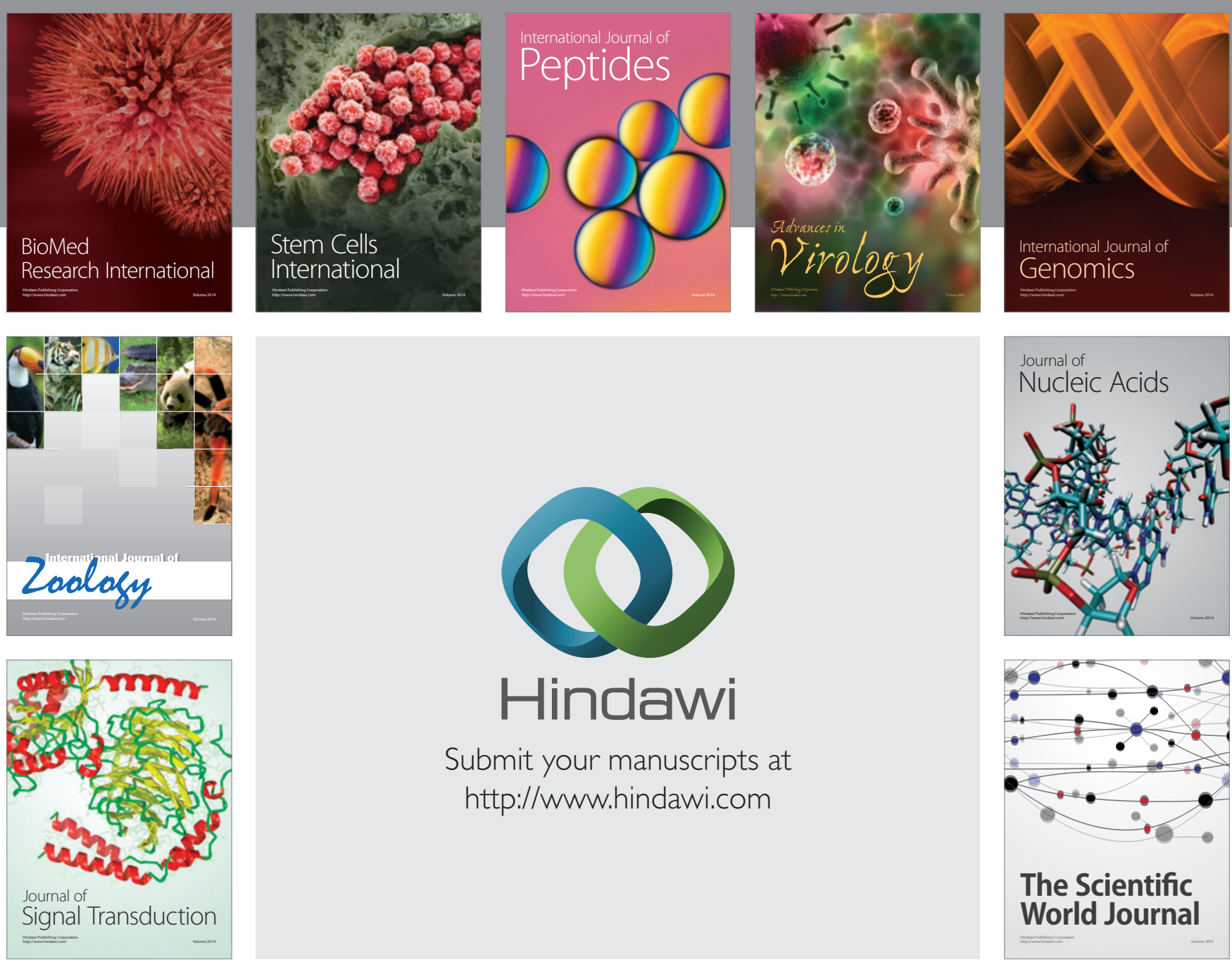

Submit your manuscripts at

http://www.hindawi.com
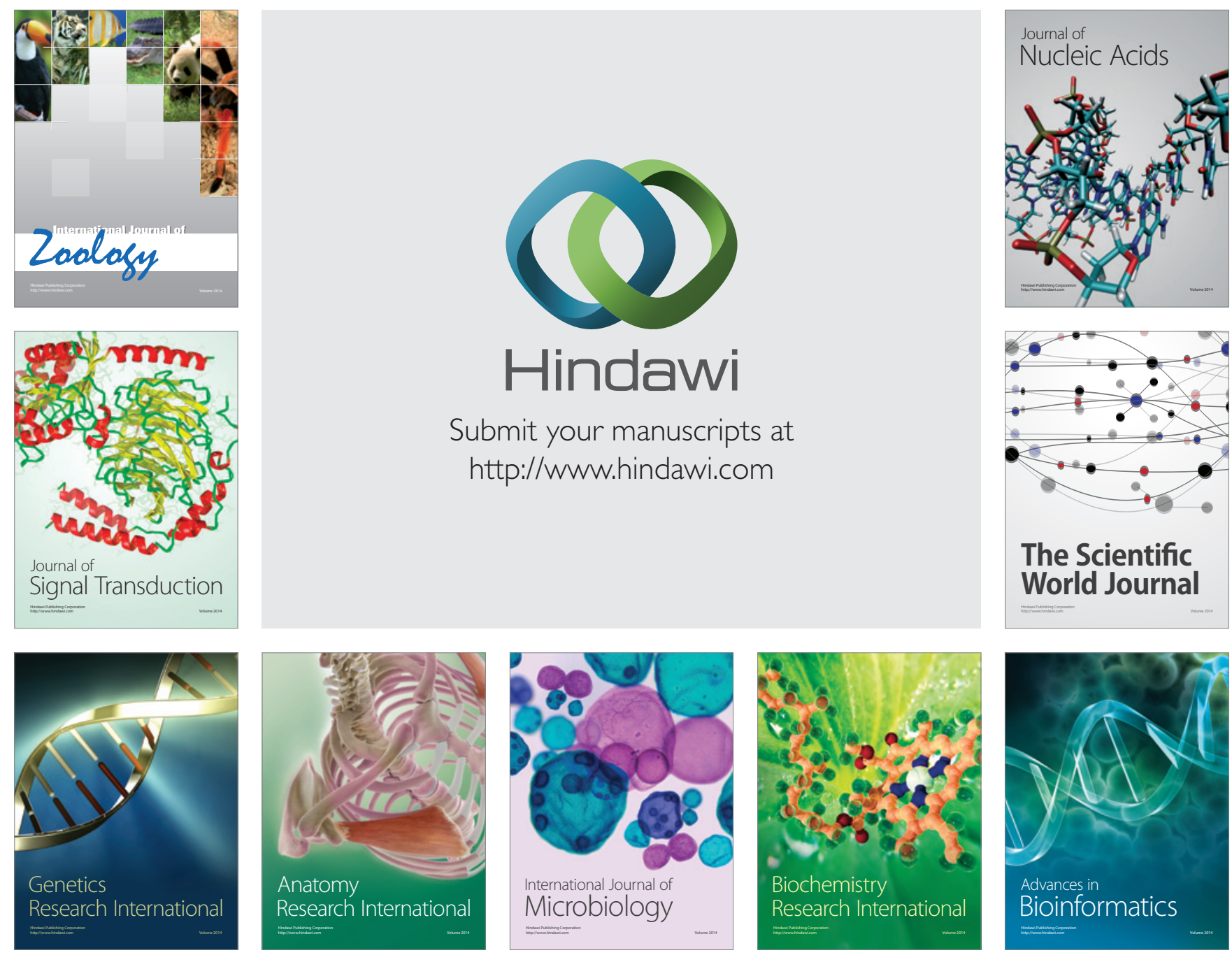

The Scientific World Journal
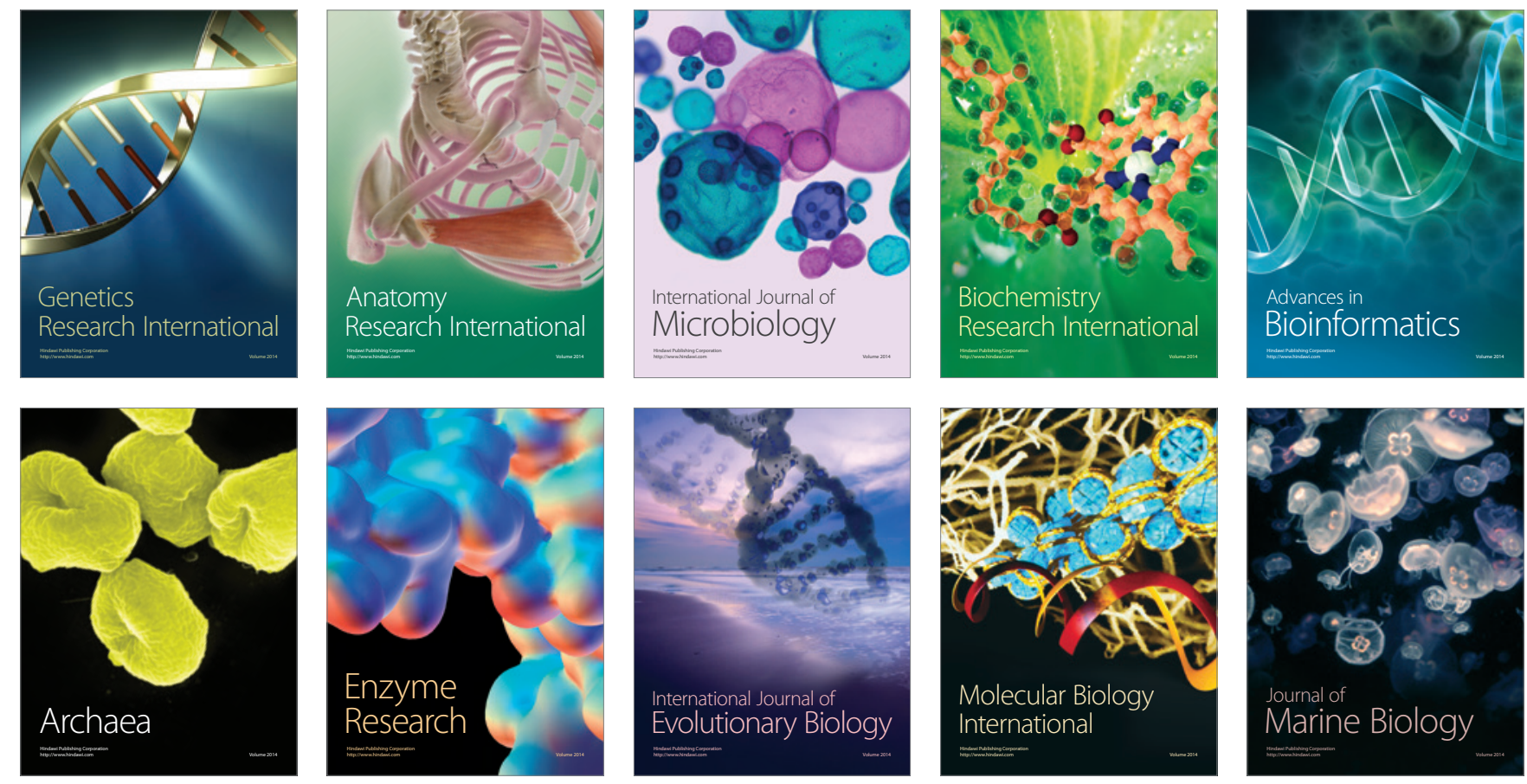